\title{
Ethical reasoning in mixed nurse-physician groups
}

Søren Holm, Peter Gjersøe, Glenn Grode, Ole Hartling, Karen E Ibsen and Henrik Marcussen University $\underset{\mathbb{\Phi}}{\mathscr{D}}$ of Copenhagen, Herlev University Hospital, Holbak Central Hospital, Vejle Central Hospital, Esbjerg Central Hospital and Ringsted Hospital respectively

\begin{abstract}
Objectives-To study the ethical reasoning of nurses and physicians, and to assess whether or not modified focus groups are a valuable tool for this purpose.

Design-Discussion of cases in modified focus groups, each consisting of three physicians and three nurses.

The discussion was taped and analysed by content analysis.

Setting-Five departments of internal medicine at Danish hospitals.

Sample-Seven discussion groups.

Main measurements-Ethical content of statements, style of statements, time used by each participant.

Results-Danish physicians and nurses do not differ in the kind of ethical reasoning they use, but physicians use more of the discussion time than nurses, they use a more assertive style of argumentation, and the solutions chosen are usually first put forward by physicians. Conclusion-The results and informal comparisons with similar data from long qualitative interviews indicate that groups of this kind are a useful tool for gathering data on ethical reasoning.
\end{abstract}

\section{Introduction}

Studies of the moral reasoning of health care personnel are usually performed as either interview or questionnaire studies, following the tradition from moral psychology. These approaches raise a number of problems.

Questionnaire studies in this area often presume a specific underlying moral theory and may confine the respondents' answers to those that are allowed within the theoretical framework. This is exemplified in the debate between proponents of Kohlberg's justiceoriented and Gilligan's care-oriented approaches to assessing moral development. ${ }^{14}$ When the justice theorists do not see "care" being used in moral reasoning by their respondents and vice versa, it may well be because of the narrow scope of their questions or analysis methods. ${ }^{5}$

\section{Key words}

Medical ethics; ethical reasoning; focus groups.
Interview studies usually allow the respondents greater latitude, but may encounter the problem of $\omega$ "conformist respondents" giving the response they $\dot{\sigma}_{\bar{D}}$ perceive as socially desirable, or may have bias ${ }^{\infty}$ caused by the "interviewer effect". ${ }^{6}$

The optimal approach would probably be a study of moral reasoning in real-life groups, discussing $\subseteq$ real-life dilemmas. Such studies are very rare, pre-ه sumably because of the problems in getting access to $\vec{\bullet}$ groups where discussions of ethical problems constitute a major part of the interaction.

We have therefore found it of interest to use aO modification of focus group techniques to study moral reasoning and attitudes in "artificial" groupso of health care personnel. ${ }^{78}$

Such an approach seems to have two methodological advantages when compared to interview andô questionnaire studies: a. Respondents are not exposed to any interviewer effect, and b. The risk of getting conformist answers may be less if the respondents have to defend their point of view in a亏 group of peers.

The group format also makes it possible to 3 study aspects of the group dynamics in a group of professionals discussing ethical questions. This may be increasingly important in an era where health care 0 systems are becoming more and more complex, and? where group decisions about care become moreo common. If group dynamics influence the clinical decisions at the bedside or in conferences, it is important to be able to study this aspect of theN decision-making process.

The present study therefore has three interrelated $\omega_{\sigma}$ aims: a. To assess the usefulness of modified focus groups in moral reasoning research; b. To studyc aspects of the group dynamics related to ethicalof decision making, and c. To assess possible differences 0 in moral reasoning between Danish nurses andō physicians.

\section{Materials and methods}

Seven discussion groups were formed at five depart- $\delta$ ments of internal medicine. Six groups consisted of three nurses and three physicians, one of two nurseso and three physicians. This composition of the groups. 
were chosen in order to: a. Facilitate the analysis of group dynamics by including members of two distinct professional groups, and $b$. Create an interaction which would make it possible to study possible differences in moral reasoning between nurses and physicians. ${ }^{9}$ The participants were all volunteers, and did not constitute a random sample of the employees at the departments included in the study. No attempt was made to ascertain whether they differed from other nurses and physicians working in the same department.

Three cases were successively presented for discussion, and the groups were asked to discuss and make a decision within a 20 -minute time limit for each case. A moderator was present to keep a list of speakers, to keep the time, and to intervene if the discussion went seriously off track. The moderator did not participate in the discussion in any other way. No attempt was made to gather additional information by participant observation.

All discussions were taped, transcribed verbatim by the same secretary, and anonymised by removal of all personal and geographical references.

The three cases presented describe the following situations:

\section{CASE 1}

Mrs Hansen was admitted to the department five days ago. She is 76 years old and lives with her husband in a large first floor apartment. She worked all her life as a teacher until she retired 11 years ago. Half a year ago she began having single episodes of pain in the right side of the abdomen, which she treated with over-the-counter analgesics and a herbal remedy. The condition has gradually become worse, and she has called her general practitioner who has started treatment based on a suspicion of "irritable colon". The treatment has only had limited effect and the doctor has admitted Mrs Hansen for further investigation.

$\mathrm{X}$-rays of the colon taken two days ago show a typical tumour-configuration in the right part of the colon, and closer examination of the chest X-rays which were routinely taken on admission raises suspicion of metastases to the lungs.

Mrs Hansen has not asked about the result of the investigations, and seems to feel at ease on the ward. When one tries to turn the conversation towards her symptoms and the investigations she has been through, she begins talking about the other patients, the weather, or her husband, who faithfully visits her every day.

At the afternoon departmental conference there is agreement that Mrs Hansen has a primary colonic cancer with metastases to the lungs, but there is disagreement about what to tell her.

What do you think?

CASE 2

Henrik Petersen is a 56-year-old carpenter. He is married and has two adult children. One year ago he was diagnosed as having small-cell anaplastic carcinoma of the lung and began chemotherapy at the department of oncology. Four months ago a recurrence was diagnosed and the patient was told by the department of oncology that they had no further treatment options for him. Since then he has been admitted once to the department of medicine with pneumonia, two months ago.

Four days ago he was again admitted with pneumonia. The condition has responded poorly to intensive antibiotic treatment, in spite of cultures of tracheal secretions showing full sensitivity to the antibiotics that are used. The patient has been somewhat confused during the entire admission due to high temperature. His general condition is assessed to be considerably worse than at his last admission two months ago.

During the rounds it is considered whether treatment should be stopped, since the expected survival of the patient, even if he recovers from the acute crisis, is judged to be only one to two months.

The patient has not expressed any attitude towards the treatment, neither during the present nor the previous admission, and his wife says that the staff should do "what is best for my husband". The physician, who is doing the rounds, therefore decides to take the question of cessation of treatment to the departmental conference.

What decision do you think should be taken?

\section{CASE 3}

The medical department of X-ville central hospital has a large out-patient clinic, and for many years has had a large special out-patient clinic for patients with insulin dependent diabetes.

Because of the closure of several small hospitals in the county both the number of admissions and the general activity in the out-patient clinic have increased substantially. There is therefore a need to increase the numbers of staff both in the out-patient clinic and on the wards. After long discussions the administration has put forward two proposals, and has demanded that the departmental management chooses between them.

1. The diabetes out-patient clinic is closed, the resources are transferred to the general out-patient clinic, and the medical wards receive a number of extra nurses.

2. The diabetes out-patient clinic is retained, the general out-patient clinic receives a number of extra nurses, but the numbers of staff on the medical wards are kept constant.

What solution do you think should be chosen?

These cases were designed to be of interest to both physicians and nurses, and to explore three important subject areas in health care ethics: truth-telling, end-of-life decisions, and resource allocation problems. 
Table 1 Coding categories

Ethical statement content categories

Deontological

Patient has a right to decide whether to hear the truth

Health care personnel has a duty of honesty

Wrong to end life actively

Teleological

Best for the patient

Best for the family

Best for the carers

Best for the population of patients

fusticelfairness

Build or maintain relationship with patient

Be responsible for patient

Statement types

Elucidating the problem/clarifying the context

Presenting or discussing technical information

Presenting conclusion

Responding to others

Linguistic styles

Assertive

Non-assertive

\section{Analysis}

The number of lines of text spoken by each participant as well as the number of utterances was counted.

A content analysis of each individual statement was performed, using the methods of semantical content analysis. ${ }^{810}$ This form of content analysis takes the meaningful statement to be the unit of analysis. A continuous segment of text is first analysed to see whether it can be broken down into smaller meaningful statements, and each of these statements is then categorised according to its semantic content (ie, its meaning).

In this study statements were categorised according to ethical content, type of statement, and linguistic style (Table 1).

The ethical content categories were developed from a previous study of the ethical reasoning of medical professionals (unpublished), from the literature ${ }^{11}$ and from the present data. The classification mainly follows the classical distinction in moral philosophy between deontological (right or dutybased) arguments and teleological (consequentialist) arguments, but also contains three categories that are not easily classified by this distinction. These three additional categories contain statements primarily concerned with: a. justice/fairness between patient groups, b. the importance of building or maintaining a good relationship with the patient where the relationship is not seen as a means to a further end but as an end in itself, and c. the obligation to be responsible for the patient, understood as a role obligation falling especially on health care professionals as part of the "internal morality" of the professions.

The analysis for linguistic style divided statements into assertive and non-assertive statements, using the approach in Tannen's Talking from Nine to Five. ${ }^{2} \mathrm{~A}$ statement was classified as assertive if it only advocated one point of view, or if other point of view were only mentioned in order to be summare ily dismissed. A statement such as: "If there are an cerebral metastates he should just get some treat: ment, then they usually get better, not well, buE better" was classified as assertive. A statement waํㅡㄹ classified as non-assertive if it admitted the possible validity of more than one point of view, or if uncero tainty was expressed regarding the conclusion that was put forward. A statement such as: "What I amb not quite certain about is, that I think, that in a way. I feel, that we agree that she should know it, but if sounds as if you think that she shouldn't quite" was classified as non-assertive. Short statements which did not permit reliable coding were not classified N Results on linguistic style are reported as the relativew number of assertive statements among the classifi $\vec{\circ}$ able statements.

The codings for content, type, and style were per을 formed after removal of the speaker identifications. $\vec{c}$ The coder was thus unaware of the profession of the speaker. The initial coding was performed by on person, and all ambiguous statements were referredo to a second person who, on the basis of the definio tions of the categories, made a final decision.

Statistical analysis was performed using the Sign? test for ratios, Fisher's exact test for discrete datas and the Mann-Whitney $U$ test for data on ordinal/interval scales. ${ }^{8}$

\section{Results}

In one of the groups only one statement was made concerning case three. This statement was put forward by a physician and everybody agreed with his conclusion. This "discussion" was not used in the analysis of content, type, and style.

The quantitative analysis shows that doctors takes up more discussion space than nurses in all severs discussion groups, and that this is a combined effect of a difference in the length of each individual utter? ance and of more utterances presented (Table 2) The same picture emerges in each individual case. discussion. In all discussions of case one, five out op seven discussions of case two, and six out of severn discussions of case three, doctors speak more than nurses.

In 17 of the 21 discussions the first intervention comes from a physician $(p=0.0072)$, and in 18 of $2 \frac{\mathrm{F}}{\mathrm{D}}$

Table 2 Division of discussion time

\begin{tabular}{|c|c|c|}
\hline $\begin{array}{l}\text { Group } \\
\text { number }\end{array}$ & $\begin{array}{l}\text { Lines of text } \\
\text { doctors/total }\end{array}$ & $\begin{array}{c}\text { Number of statemen } \\
\text { doctors/total }\end{array}$ \\
\hline $\begin{array}{l}1 \\
2 \\
3 \\
4 \\
5 \\
6 \\
7\end{array}$ & $\begin{array}{r}.631 \\
.769 \\
.542 \\
.720 \\
.544 \\
.637 \\
.649\end{array}$ & $\begin{array}{r}.549 \\
.674 \\
.554 \\
.671 \\
.486 \\
.593 \\
.576\end{array}$ \\
\hline
\end{tabular}




\begin{tabular}{|c|c|c|c|c|c|c|}
\hline & \multicolumn{2}{|c|}{ Case 1} & \multicolumn{2}{|c|}{ Case 2} & \multicolumn{2}{|c|}{ Case 3} \\
\hline & $P^{\star}$ & $N$ & $P^{\star}$ & $N$ & $P 4$ & $N$ \\
\hline $\begin{array}{l}\text { Deontological } \\
\text { Patient has a right to decide whether or not to be told the truth } \\
\text { Health care personnel has a duty of honesty } \\
\text { Wrong to end life actively }\end{array}$ & $\begin{array}{r}13 \\
4 \\
0\end{array}$ & $\begin{array}{l}4 \ddagger \\
2 \\
0\end{array}$ & $\begin{array}{l}0 \\
2 \\
8\end{array}$ & $\begin{array}{l}0 \\
2 \\
5\end{array}$ & $\begin{array}{l}0 \\
1 \\
0\end{array}$ & $\begin{array}{l}0 \\
0 \\
0\end{array}$ \\
\hline $\begin{array}{l}\text { Teleological } \\
\text { Best for the patient } \\
\text { Best for the family } \\
\text { Best for the carers } \\
\text { Best for the population of patients }\end{array}$ & $\begin{array}{r}18 \\
10 \\
6 \\
0\end{array}$ & $\begin{array}{r}18 \\
11 \\
4 \\
0\end{array}$ & $\begin{array}{r}11 \\
17 \\
6 \\
1\end{array}$ & $\begin{array}{r}13 \\
18 \\
5 \\
1\end{array}$ & $\begin{array}{r}4 \\
0 \\
5 \\
11\end{array}$ & $\begin{array}{l}3 \\
0 \\
2 \\
8\end{array}$ \\
\hline $\begin{array}{l}\text { Justice/fairness } \\
\text { Build or maintain relationship with patient } \\
\text { Be responsible for patient }\end{array}$ & $\begin{array}{r}0 \\
10 \\
13\end{array}$ & $\begin{array}{r}0 \\
11 \\
9\end{array}$ & $\begin{array}{r}0 \\
5 \\
11\end{array}$ & $\begin{array}{l}0 \\
9 \\
6\end{array}$ & $\begin{array}{l}9 \\
1 \\
8\end{array}$ & $\begin{array}{l}5 \\
2 \\
2\end{array}$ \\
\hline
\end{tabular}

$\mathrm{P}=$ number of physicians using this concept; $\mathrm{N}=$ number of nurses using this concept. ${ }^{\star} \mathrm{N}$ (physicians) $=21, \mathrm{~N}($ nurses) $=20$; $+\mathrm{N}$ (physicians) $=18 ; \mathrm{N}$ (nurses) $=17 ; \neq \mathrm{p}=0.0149$ (Fisher's exact test).

$(p=0.0015)$ the solution finally agreed upon is first explicitly proposed by a physician (although usually not in the first intervention).

The solutions chosen were not the same in all groups. In case one four groups decided to wait and tell the patient the truth later or maybe not at all, and three groups decided that the patient should be told. In case two four groups would continue the planned course of antibiotics but not do anything more, two groups would stop treatment now, and one group would order further investigations. In case three three groups chose proposal one, three groups proposal two, and one group would propose a compromise.

The analysis of ethical content showed no major differences between nurses and physicians, except in case one where physicians were significantly more likely to put forward a specific deontological statement (Table 3).

An informal comparison with data from a previous qualitative interview study (unpublished) indicates that the richness and depth of the ethical statements/arguments are at least comparable to that of interview data.

No differences were found in the type of statements put forward by the two professional groups, but it was found that quite a large proportion of statements were, at least partially, concerned with elucidating the nature of the ethical problem, clarifying the context, or presenting or discussing technical information (Table 4). In case one these statements were concerned with the mental state of the patient, and with the consequences of not telling her that she had cancer (whether she would later need an operation for

Table 4 Proportion of clarifying or technical statements

\begin{tabular}{llll}
\hline & Case 1 & Case 2 & Case 3 \\
\hline $\begin{array}{l}\text { Elucidating the problem or } \\
\text { clarifying the context }\end{array}$ & 0.384 & 0.270 & 0.189 \\
$\begin{array}{c}\text { Presenting or discussing } \\
\text { technical information }\end{array}$ & 0.121 & 0.223 & 0.357 \\
\hline
\end{tabular}

intestinal obstruction). In case two the statements were concerned with the patient's knowledge of his impending death, his prospective quality of life, and the family dynamics in the patient's family, as well as with the chance that a few more days of antibiotic treatment would cure his pneumonia. In case three the statements addressed the problem of whether health care personnel had a duty to speak out against unreasonable proposals, what chance a compromise proposal might have, and what proposal would affect patients the least.

The style analysis shows that physicians use the assertive style more frequently than nurses. Of the statements which could be classified for style a median of $79 \cdot 1 \%$ of the statements made by physicians were assertive compared to $49 \cdot 7 \%$ of the statements made by nurses $(p=0.0024$, Mann-Whitney test).

\section{Discussion}

In the Danish health care system physicians and nurses are salaried employees of the hospital, and patients do not "belong" to any specific consultant. Important treatment decisions are most often made at a departmental conference with the participation of a number of physicians and nurses.

The group format used in this study resembles the format of these departmental conferences, although the time for discussion here was longer than is normally available.

Participants in this study are therefore used to this format, and there are no indications in the data that they are hesitant in engaging in discussion.

The different solutions reached in the different groups furthermore indicate that the three cases used here describe real moral dilemmas.

Evaluated as a tool for the study of moral attitudes and moral reasoning among health care personnel, discussion groups of this kind can therefore be useful because they allow for the collection of a large amount of rich data, data which is suitable for both 
quantitative and qualitative analysis. However, if a strictly quantitative analysis is intended only one case should be presented, since it is difficult to account for the influence of previous discussions in the same group in the analysis.

The present study used fairly detailed case descriptions, but the participants still used a fair amount of the discussion to clarify the exact context. This finding may have implications for studies in empirical ethics, where participants are asked to respond to case descriptions. Such case descriptions are rarely more detailed than the ones used here. If the present cases need clarification before an ethical conclusion can be reached, this could affect the reliability of research using cases that are less detailed. The answers may not be related directly to the case presented, but instead to the case combined with extra contextual features added by the respondent.

The results show that the agreement which is reached centres around proposals put forward by physicians. This cannot be explained by the types of ethical arguments which physicians put forward, since the content analysis of ethical statements indicates that there are no great differences between physicians and nurses in this area. Within the format of these groups hierarchical position played no direct role, ie nobody could impose his or her will on the group through a claim to authority, but of course there may be a residual implicit authority imported into the group from the normal hierarchical structure of health care settings or from the more general difference in the social status of physicians and nurses. It is, however, important to note, that although hierarchies exist both among doctors and among nurses in the Danish health care system, the distribution of power and authority between doctor and nurses cannot be reduced to a simple model where doctors automatically have authority. ${ }^{14} 15$

The findings are, however, fully explainable by the differences found in linguistic style and appropriation of discussion space. Because physicians are the first to intervene they can set the stage for the discussion, and their use of longer and more assertive statements is a more effective strategy in settings where the outcome is primarily measured in terms of effective decision-making and not in terms of favourable group dynamics. ${ }^{12}$

This result is not in itself surprising. It is well known from social psychology that status, influence, and appropriation of discussion space co-vary. ${ }^{16}$ From an ethical point of view the result could, however, be problematic. If the ideal in ethical decision-making is unforced consensus, ${ }^{17}$ or at least a reasoned compromise, then we will have to look for decision-making procedures where the importance of formal or informal status is reduced. It is beyond the scope of the present paper to suggest how this might be done.

The dominance of doctors in the discussion could also have implications for the validity of the method.
If the decisions of the nurses were influenced by the doctors, one could argue that the data related tợ? their ethical reasoning might be less reliable than similar data gathered through individual interviews? This objection cannot be refuted on theoretica? grounds. If nurses just accepted the proposals ance arguments put forward by doctors without discus $\frac{\vec{\Phi}}{\overline{0}}$ sion, the reliability of the data with regard to the nurses ethical reasoning would be minimal. This is however, not the case. Twenty of the 21 discussions were "real" discussions with long exchanges of arguments and counter-arguments. There is goodw reason to believe that the individual participants? were presenting the best possible case for their point of view, and that they were putting forward the ethical arguments they perceived as most cogent. $\omega$

None of the participants used only deontologicat or only teleological arguments in their ethicapo reasoning. Both kinds of arguments, as well as othes categories of arguments which are not easily classifiable by this classic distinction, were used inter changeably, and were sometimes mixed within the same statement. In their moral reasoning health car personnel are neither consistently consequentialist nor consistently non-consequentialist. Their morab universe contains both kinds of considerations, as well as considerations about the importance of building or maintaining relationships with patients and about a professional responsibility towards the patients and their families. This finding agrees with findings from a long range of interview studies perô formed within the cognitive development and sociap learning traditions in moral development research.

The different choices made in these fairly similar: groups indicate that the different moral considera tions are played off against each other in complex ways, and there do not seem to be any simple priority rules which can resolve the participants ethical worries.

\section{Acknowledgements}

This research was supported by Anna og Jakol? Jakobsens Legat, Direcktør Jacob Madsen og Hustrw్ Olga Madsens Ford, Fonden af 1870, and Lægeforeningens Forskningsfond. Søren Holm wa\&u supported by a research fellowship from the University of Copenhagen, Faculty of Healti Sciences. We thank the Editor and two anonymous referees for helpful comments on an earlier versiom of this paper.

Soren Holm, MA, MD, is Senior Research Fellow in th Department of Medical Philosophy and Clinical Theory University of Copenhagen. Peter Gjersee is Registrar of the Department of Gastroenterology, Herlev Universit Hospital. Glenn Grode is Consultant at the Department of Internal Medicine, Holbak Central Hospital. Hartling is Consultant at the Department of Clinice Physiology, Vejle Central Hospital. Karen E Ibsen 
Senior Registrar at the Department of Internal Medicine, Esbjerg Central Hospital. Henrik Marcussen is Consultant at the Department of Internal Medicine, Ringsted Hospital.

\section{References}

1 Kohlberg L. The philosophy of moral development [vol 1]. San Francisco: Harper \& Row, 1981.

2 See reference 1: vol 2.

3 Rest JR. Development in judging moral issues. Minneapolis: University of Minnesota Press, 1979.

4 Gilligan C. In a different voice. Cambridge, MA: Harvard University Press, 1982.

5 Self DJ, Skeel JD. Facilitating healthcare ethics research: assessment of moral reasoning and moral orientation from a single interview. Cambridge Quarterly of Health Care Ethics 1992; 1: 371-6.

6 Fowler FJ. Survey research methods [2nd ed]. Applied Social Research Methods Series [vol 1]. Newbury Park, CA: Sage, 1993.

7 Morgan DL. Focus groups as qualitative research. Sage University Paper Series on Qualitative Research Methods [vol 16]. Newbury Park, CA: Sage, 1988.

8 Stewart DW, Shamdasani PN. Focus groups - theory and practice. Applied Social Research Methods Series [vol 20]. Newbury Park, CA: Sage, 1990.
9 Kitzinger J. The methodology of focus groups: the importance of interaction between research participants. Sociology of Health and Illness 1994; 16: $103-21$.

10 Janis IL. The problem of validating content analysis. In Lasswell HD, Leites N, eds. Language of politics: studies in quantitative semantics. Cambridge, MA: MIT Press, 1965: 55-82.

11 Omery AK. The moral reasoning of nurses who work in the adult intensive care setting. Unpublished Dr NSc thesis, Boston University, 1985.

12 Tannen D. Speaking from nine to five. New York: William Morrow and Company, 1994.

13 Siegel S, Castellan NJ. Nonparametric statistics for the behavioral sciences. New York: McGraw-Hill, 1988.

14 Borum F. Organisation, magt og forandring. København: Nyt Nordisk Forlag, 1976.

15 Eriksen H, Ulrichsen H. Tre kulturer $i$ hospitalssektoren. København: Nyt Nordisk Forlag, 1991.

16 Mednick SA, Higgins J, Kirschenbaum J. Psychology explorations in behavior and experience. New York: John Wiley \& Sons, 1975.

17 Moreno JD. Deciding together - bioethics and moral consensus. New York: Oxford University Press, 1995.

18 Self DJ, Baldwin DC. Moral reasoning in medicine. In: Rest JR, Narváez D, eds. Moral development in the professions. Hillsdale, NJ: Lawrence Erlbaum Associates, 1994: 147-62.

\section{News and notes}

\section{Institute of Medicine, Law and Bioethics}

The universities of Liverpool and Manchester, together with the North West Regional Health Authority, have established the Institute of Medicine, Law and Bioethics to ensure that the ethical and legal dimensions of biomedical science and health care develop "with the same vigour and priority as scientific advance and patient care".

The institute intends to establish a programme of research and education to enhance the quality and effectiveness of health care delivery in the region and throughout the UK through the promotion of safe, ethical and cost-effective practice.

For more information phone: The University of Liverpool, 0151794 2302, Fax: on 0151794 2311; The University of Manchester, 0161275 7703, Fax: 01612757704. 